\section{The distribution of Himalayan Newts, Tylototriton verrucosus in the Punakha- Wangdue Valley, Bhutan}

\author{
Jigme Tshelthrim Wangyal ${ }^{1}$ \& Dhan Bahadhur \\ Gurung ${ }^{2}$
}

${ }^{1}$ District Forest Office, District Administration, Trashigang 42001, Bhutan

${ }^{2}$ College of Natural Resources, Royal University of Bhutan, Lobesa, Punakha 14001, Bhutan

Email: ${ }^{1}$ jigmewangyal@gmail.com (corresponding author), 22dbg2006@gmail.com

The Himalayan Newt Tylototriton verrucosus is considered one of the most primitive species amongst living Salamanders (Das 1987) and is also the only salamander known from Bhutan. John Anderson, who described the species in 1871 , discovered the species in flooded rice fields near the small Chinese town of Nantin.

Although a well studied species, the Himalayan

Date of publication (online): 26 October 2012

Date of publication (print): 26 October 2012

ISSN 0974-7907 (online) | 0974-7893 (print)

Editor: Sanjay Molur

Manuscript details:

Ms \# 03136

Received 25 March 2012

Final received 05 October 2012

Finally accepted 07 October 2012

Citation: Wangyal, J.T. \& D.B. Gurung (2012). The distribution of Himalayan Newts, Tylototriton verrucosus in the Punakha-Wangdue Valley, Bhutan. Journal of Threatened Taxa 4(13): 3218-3222.

Copyright: (c) Jigme Tshelthrim Wangyal \& Dhan Bahadhur Gurung 2012 Creative Commons Attribution 3.0 Unported License. JoTT allows unrestricted use of this article in any medium for non-profit purposes, reproduction and distribution by providing adequate credit to the authors and the source of publication.

Acknowledgements: We would like to, in no particular order, thank the following individuals. Yeshi Phuntsho in Gasa and Punakha areas; Yeejay, Nima Gyeltshen and Dorji Namgay in Lamperi, Thinleygang and Dochula areas; Namgay Tshering (Gathpoo) in Sha areas. They have helped us collect and take measurements of the specimens and have never denied befriending us even at the middle of the nights. Sonam Dorji (GP), Baep Tshering and few others accompanied us to the field in Thinleygang when in the College, our sincere thanks to them. AP Sonam of Goemkha Village, Toebisa helped us catch at least four species, thanks to his spirited search for the animals. Thanks are also due to all people of the study areas. The first author in particular is glad to receive the assistance of the Rufford Small Grant for the study of this group of animals. Phurba Lhendup, WWF Bhutan programme needs a special mention for generously allowing me to use his camera during the study.

ZooBank urn:Isid:zoobank.org:pub:2FF1568B-2804-400D-95743D366EE6C5F6

\section{OPEN ACCESS | FREE DOWNLOAD}

Newts' occurrence is hardly known in Bhutan because of poor reporting. After Frost (1985), who reported the presence of the species without any specific location, Palden (2003), confirmed its occurrence in Thinleygang and Kabjisa areas. Other than these two reports, there is no evidence to prove that the species has been ever studied in Bhutan. However, outside Bhutan, the species is reported from China, India, Nepal and Thailand.

Therefore, this study was taken up in the PunakhaWangdue Phodrang Valley solely to look at the distribution and habitat of the species.

\section{Materials and Methods}

In this survey, a time-constrained visual encounter search technique (Campbell \& Christman 1982; Corn \& Bury 1989) was used because of the study areas' diverse habitat types such as paddy fields, roadsides, river banks and forests (Fig. 1). The search area within the valley was not fixed as species encountered anywhere within the valley was considered for distribution mapping.

Nocturnal road cruising and opportunistic collecting was the primary method used for collection of data. Rainy nights were taken as an advantage to catch the newts that move along the roads. While short distances were covered by walking, longer distances were covered using a car. Survey teams of two to three people used a walk-and-turn method to survey all of the area within the study site. A team of two people was used for scouring every paddy field and they walked in and around the entire field looking for the species. The observers used headlamps to continuously search the ground surface, only stopping to gently turn objects that could be easily lifted and replaced without significant disturbance to the forest floor in search of the animals.

The forest floor, on and under fallen wood, under barks, exposed rocks, tree trunks and stumps were searched for the newts and when encountered captured by hand. For further analysis, each individual was placed in buckets with a small amount of water, wet leaves or moss and they were weighed, measured, and released at their capture locations. A total of about 80 adult newts were collected from different localities of Toebisa ( $\mathrm{n}=37)$, Kabjisa $(\mathrm{n}=20)$ and Kazhi $(\mathrm{n}=23)$. 


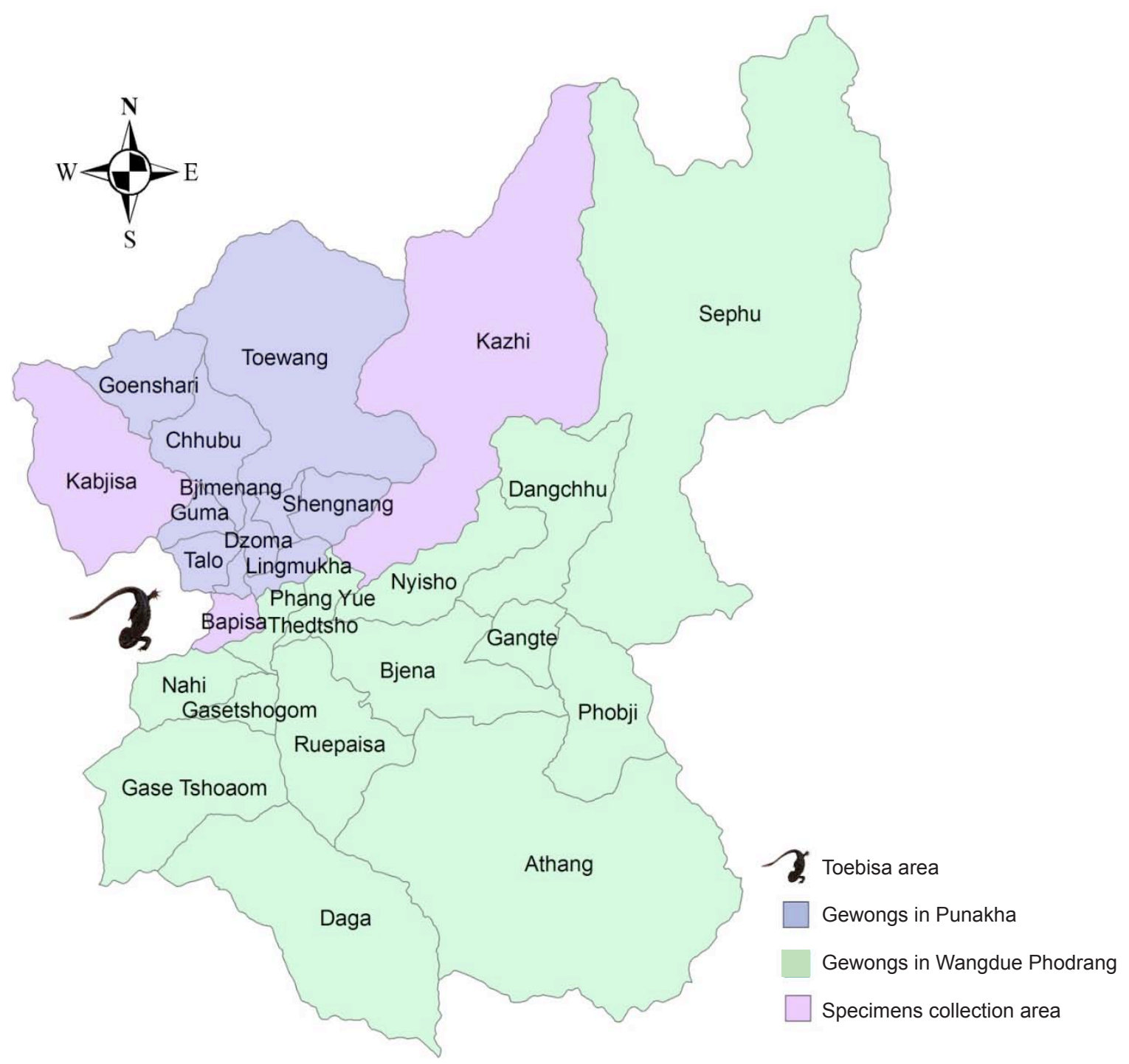

Figure 1. Study area with Gewogs from where specimens were collected. ๑ Jigme Tshelthrim Wangyal

A steel ruler was used by laying it along the length of each salamander and total length and snout-ventlength (SVL) were recorded to the nearest millimetre (mm). SVL was recorded from the tip of the snout to the front of the vent (Corkran \& Thomas 1996) and the tail length was calculated. Each newt was weighed in the bag to the nearest $0.1 \mathrm{~g}$ with a branded spring scale and then each bag was weighed separately after the animal was released. Garmin E-trek GPS was used to collect the geo-coordinates of all the species collected and their major habitats.

The identification references used in the field include Smith (1931, 1935, 1943), Daniels (2005), Yang \& Rao (2008), Ahmed et al. (2009), Fei et al. (2010), and Vasudevan \& Sondhi (2010).

\section{Results}

Frost (1985), without any specific location, reported the presence of Himalayan Newts in Bhutan which was later confirmed by Palden (2003). After that, there was no reports on the species from Bhutan. However, the lack of reports did not mean the species have gone missing. The newts did exist in the valley but without the attention of conservationists and academicians. Therefore, this study further confirms their presence.

This research showed that quite a good number of the species survive in Toebisa and Kabjisa, Punakha District, from where it was reported to the world (Palden 2003) for the first time. Kazhi, another study site under Wangdue Phodrang also had a good population of the newts. The highest elevation at which Himalayan Newts were detected was at $2679 \mathrm{~m}$, 
at Lampelri Botanical Park, below Dochula while the lowest was at Toebrongchu Zam, 1255m.

Sex ratio: To look at the sex ratio, males and females were identified amongst the collected specimens. The males carry a vertical fissure in the anal region whereas the females bear a circular opening, a clear distinction between the sexes keeping confusion out of question. Of the 37 specimens from Toebisa, 21 were males, while in Kabjisa and Kazhi the number of males was 10 out of 20 and 13 out of 23 in their respective collections. While the sex ratio in Kabjisa is $1: 1$, the males exceeded females in Toebisa and Kazhi (Fig. 2).

According to a breeding study conducted by Roy \& Mushahidunnabi (2001), oviposition happen in May and June soon after salamanders emerge from their hibernation with the first monsoon shower amongst the permanent and temporary pools, shallow ditches, marshes and slow-moving streams. In line with their finding, it is fair to assume that mating and courting ends by July which means the individual species are on their own. It can also be assumed that the sex ratio in the July collection could be skewed due to the tendency of males and females staying in groups of their own sex. An all male group of five newts was collected from Thinleygang at the end of July in 2009 (Image 1) which indicates that the species had stopped courtship and that they were on their own, looking for food and shelter.

Habitat affinity: Habitat occupancy was considered

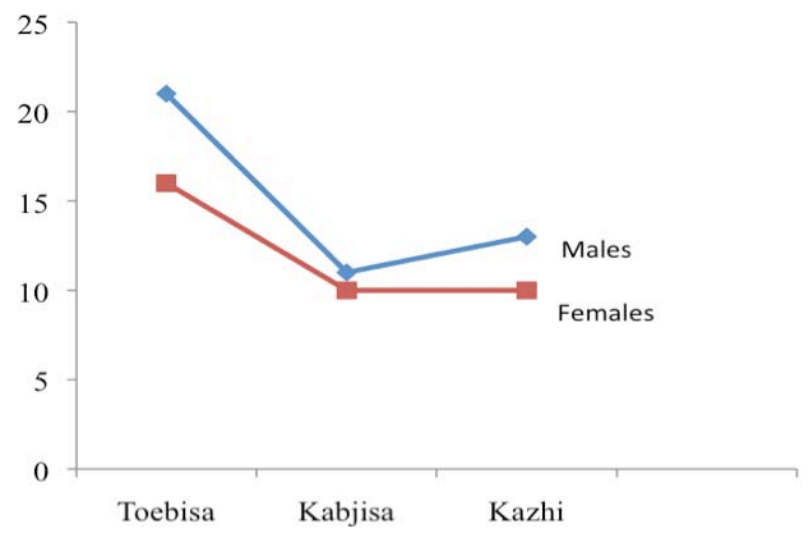

Figure 2. Ratio of males to females in the three populations

based on the number of species that were collected from three different kinds of habitat in all three study sites (Table 1). The Himalayan Salamanders seemed to like paddy fields, at least during the three months of June, July and August as most of the specimens were caught from the paddy field in all three study sites.

Since the study was conducted in July and August, the specimen collection time probably must have coincided with the phase of the species when it becomes aquatic. This is very much in consistence with the findings of the studies on the species conducted by the researchers in India who found the species becoming terrestrial once the rain ceased to fall by the end of October (Das 1987). It is only during the rains that the species breeds and remains active. Otherwise, the species is known to be sluggishly terrestrial, inclined

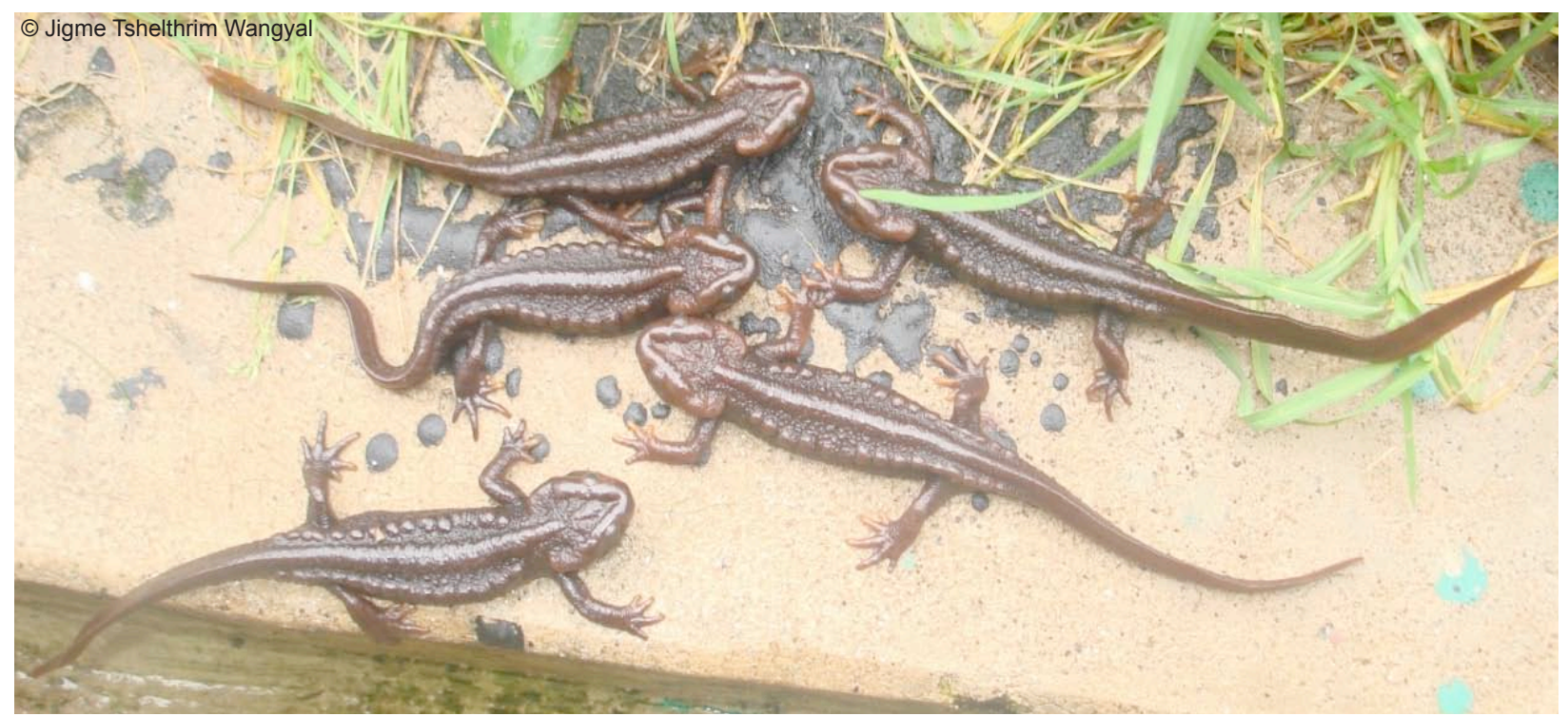

Image 1. An all male group of five Salamanders from the 2009 collection 
Table 1. Number of specimens collected from different habitats

\begin{tabular}{|c|c|c|c|}
\hline Study Areas & Roadside & Paddy field & Forest \\
\hline Toebisa & 7 & 25 & 5 \\
\hline Kabjisa & 7 & 10 & 3 \\
\hline Kazhi & 2 & 18 & 3 \\
\hline
\end{tabular}

more towards land than water.

Individuals use paddy fields for feeding and breeding while they use forests and roadsides only for migration, because maximim numbers were collected in paddy fields in all three study sites through the survey in July and August (Fig. 3). Studies in India have confirmed its egg laying period as the last week of June on leaves of submersed aquatic plants. The eggs hatch by the middle of July and by the last week of August they become big enough for a terrestrial life. This study conforms with Das (1987). However, the soil data analysis result which showed the soil to be basic could not be used due to nonavailability of past records for comparative analysis.

Personal observations of the animals over the last few years has revealed that the animals are most active in June and July when the paddy plantation and weeding of the fields happen. The newts of this locality are very active by day, as many could be observed during the day in the paddy fields. The villages of Lemjikha and Thinleygang in Toebisa Gewong were scoured mostly during the day as their paddy fields provided the best possible sites for catching the salamanders in situ for morphometric studies.

Association with other species: In this study, the Himalayan Newts were found along with Polypedates cf. himalayensis in all three study sites. In Toebisa, the species found alongside the newts included Xenophrys cf. nankiangensis, Duttaphrynus melanostictus and Nanorana liebigii. In Kabjisa, the associates included D. melanostictus, D. himalayanus and N. liebigii while in Kazhi, the sympatric species included $D$. melanostictus and D. himalayanus.

The sympatric occurrences of Duttaphrynus and Rana tadpoles, juvenile $D$. himalayanus and foam nests of rhacophorid frogs have been observed in Nepal (Schleich \& Kästle 2002). Similarly, the sharing of aquatic habitat with the metamorphosing Polypedates cf. himalayensis was observed in Kabjisa. Many other sympatric species must have been left out owing to the

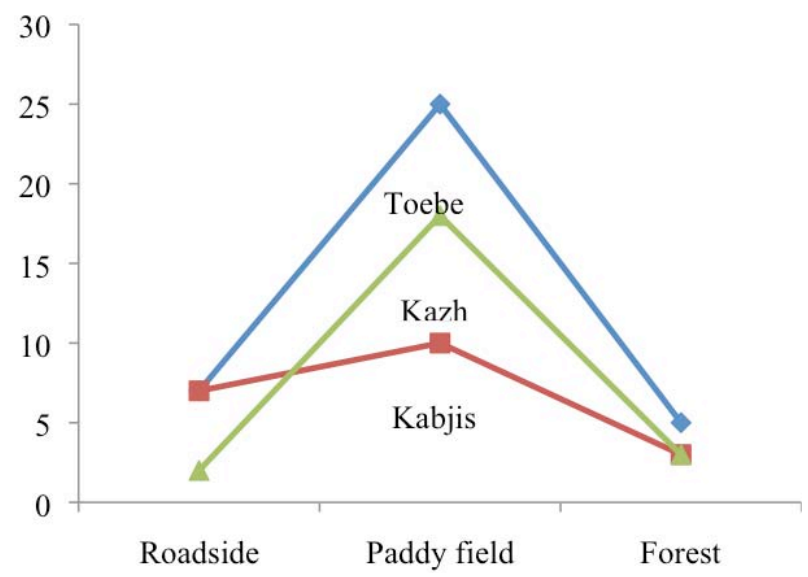

Figure 3. Comparison of newts' affinity to different habitats

short duration of the study because the newts cover extensive areas around the vast paddy fields where there are chances of getting several species of other amphibians if a long term study is done.

Distribution: The salamanders were found in Kabjisa, Barp, Toep, Chhubu, Dzomi, Guma, Shengana, Talo, and southern Toewang in Punakha Dzongkhags. The species was not seen in Lingmukha while Goenshari was not surveyed.

In Wangdue Phodrang, the majority of the animals were observed in Kazhi, Nahi and Thedtsho while Gewongs like Bjena, Nyisho, Gangtey, Phangyul and Rubeisa were not properly surveyed due to time constraints. The rests of the Gewongs were not even visited.

This study also shows that Himalayan Salamanders occur along small seasonal and perennial stream reaches and paddy fields from $1255-2679 \mathrm{~m}$. Therefore, these habitats (streams and paddy fields) must be conserved. The traditional paddy farming must continue for the survival of the species as the fields provide them food, shelter and home. The distribution map (Fig. 4) shows the areas where the species were found during the study. These areas are significant for conservation of the Himalayan Newts.

\section{Conclusion and Discussions}

This study, being the first of its kind in Bhutan is significant and is an attempt to find the habitats of the Himalayan Newts in the Punakha-Wangdue Valley. The species was found to use paddy fields, vernal pools, streams and forest sides.

A look at the sex ratio revealed that the males 


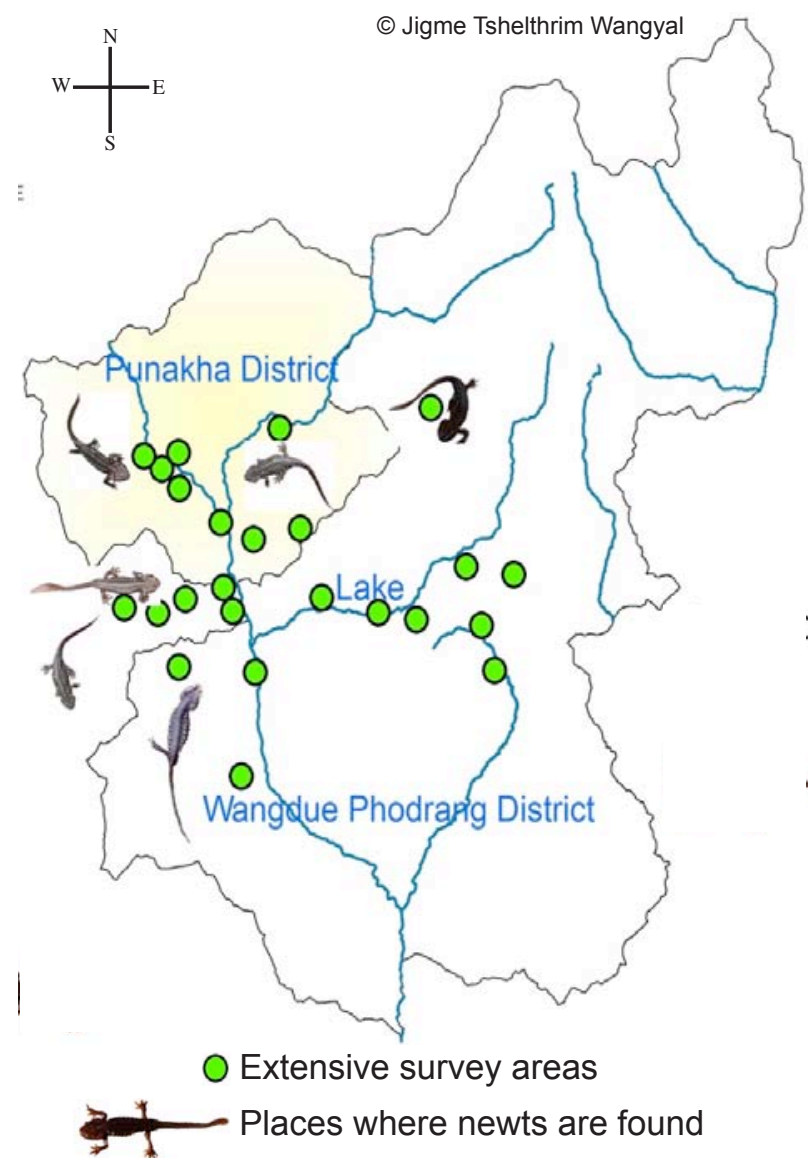

Figure 4. The distribution of Himalayan newts in the valley

exceeding the females by a small margin, is not a worrying factor for the species' survival. By way of habitat affinity, the newts seemed to like the paddy fields, at least during the summer when the fields are being worked for paddy production. Almost all the specimens came from the paddy fields. Looking at the association with other species, the Himalayan Newts were found along with the Polypedates cf. himalayensis in all three study sites including other species such as Xenophrys cf. nankiangensis, Duttaphrynus melanostictus, D. himalayanus and Nanorana liebigii.

Distribution wise, the study showed that Himalayan Salamanders occur along small seasonal and perennial stream reaches and paddy fields from 1255-2679 m. Therefore, these habitats (streams and paddy fields) must be conserved. The traditional paddy farming must continue for the survival of the species as the fields provide food, shelter and home for the Himalayan Newts.

\section{REFERENCES}

Ahmed, M.F., A. Das \& S.K. Dutta (2009). Amphibians and Reptiles of Northeast India: A Photographic Guide. Aaranyak, Society for Biodiversity Conservation. 50 Samanwoy Path, Survey, Beltola, Guwahati, Assam, India, 168pp.

Campbell, H.W., \& S.P. Christman (1982). Field techniques for herpetofaunal community analysis, pp. 193-200. In: Scott, N.J. Jr. (ed.). Herpetological Communities. Wildlife Research Report 13, U.S. Department of the Interior, Fish and Wildlife Service

Corn, P.S. \& R.P. Bury (1989). Logging in western Oregon: responses of headwater habitats and stream amphibians. Forest Ecology and Management 29: 39-57.

Cockran, C. \& C. Thoms (1996). Amphibians of Oregon, Washington and British Columbia: A Field Identification Guide. Lone Pine Pub., Edmonton, 175pp.

Daniels, R.J.R. (2005). Amphibians of Peninsular India. University Press (India) Private Limited. 3-5-819 Hyderguda, Hyderabad, 169pp.

Das, I. (1987). Natural history of the Indian Salamander. Herpetofauna News 9: 3.

Fei, L., C. Ye, \& J. Jiang (2010). Coloured Atlas of Chinese Amphibians. Sichuan Publishing Group. Sichuan Publishing House of Science and Technology, China, 517pp.

Frost, D.R. (1985). Amphibian Species of The World. A Taxonomic and Geographic Reference. Allen Press, Inc., and Associations of Systematic Collections, Lawrence, (iv) $+\mathrm{v}+732 \mathrm{pp}$.

Palden, J. (2003). New records of Tylototriton verrucosus Anderson, 1871 from Bhutan. Hamadryard 27: 286-287.

Roy, D., \& Md. Mushahidunnabi (2001). Courtship, mating and egg-laying in Tylototriton verrucosus from the Darjeeling District of the Eastern Himalaya. Current Science 81(6): 693-695.

Schleich, H.H. \& W. Kästle (eds.) (2002). Amphibians and Reptiles of Nepal. Biology, Systematics, Field Guide. A.R.G. Gantner Verlag K.G., Ruggell, Germany. Koenigstein: Koeltz Scientific Books, 1,200pp.

Smith, M.A. (1931). The Fauna of British India, Ceylon and Burma: Amphibia and Reptilia, Vol.I. - Loricata, Testudines. ( $1^{\text {st }}$ edition). Taylor and Francis Ltd. London, 185pp.

Smith, M.A. (1935). The fauna of British India, Ceylon and Burma: Amphibia and Reptilia, Vol.II. - Sauria. ( $1^{\text {st }}$ edition). Taylor and Francis Ltd. London, 440pp.

Smith, M.A. (1943). The fauna of British India, Ceylon and Burma, including the whole of the Indo - Chinese region. Reptilia and Amphibia. Vol. III. Serpentes. Taylor and Francis, London, i-xii+583pp+1 map.

Vasudevan, K. \& S. Sondhi (2010). Amphibians and Reptiles of Uttarakhand, India. Wildlife Institute of India, Chandrabani 18, Dehradun, Uttarakhand, India, 94pp.

Yang, D. \& D. Rao (2008). Amphibia and Reptilia of Yunnan. Yunnan Publishing Group Corporation, Yunnan Science and Technology Press, Kunming (in Chinese), 12-152pp. 